\title{
Isolated Ascending Colon Varix: An Unusual Cause of Lower Gastrointestinal Bleed
}

\author{
Jahnvi Dhar ${ }^{1}$ Jayanta Samanta ${ }^{1, \odot ~ G a u r a v ~ M u k t e s h ~}{ }^{1} \quad$ Rakesh Kochhar $^{1}$
}

1Department of Gastroenterology, Postgraduate Institute of Medical Education and Research, Chandigarh, India

\begin{abstract}
Address for correspondence Jayanta Samanta, MD, DM, Department of Gastroenterology, Post Graduate Institute of Medical Education and Research, Sector -12 , Chandigarh 160012, India (e-mail: dj_samanta@yahoo.co.in).
\end{abstract}
Abstract Keywords
- portal hypertension
- cirrhosis
- ectopic varix
- lower gastrointestinal bleed

Ectopic varices, defined as dilated portosystemic veins located at unusual sites other than the gastroesophageal junction and fundus, have been reported in cases of cirrhosis with underlying portal hypertension. The common sites usually are the rectum and duodenum. Isolated colon varix is therefore a rare phenomenon and such varix presenting with lower gastrointestinal bleed as the first manifestation is still uncommon. A high index of clinical suspicion, timely imaging with full-length colonoscopy, and subsequent endoscopic therapy can effectively manage this rare entity.

\section{Brief Clinical Scenario}

A 50-year-old gentleman, known case of alcohol-related cirrhosis, presented with gastrointestinal (GI) bleed in the form of melenic stools and fresh blood per rectum for 15 days. On evaluation, his vitals were stable, and investigations revealed low hemoglobin $(5.6 \mathrm{~g} / \mathrm{dL}$ ), deranged renal functions (creatinine $=2.6 \mathrm{mg} / \mathrm{dL})$, low albumin $(2.1 \mathrm{~g} / \mathrm{dL})$, and coagulopathy (international normalized ratio [INR]-1.43). There was no history of prior hematemesis or prolonged analgesic intake. After initial resuscitation, including blood transfusions and intravenous antibiotics, esophagogastroduodenoscopy was performed, which revealed absence of esophageal, gastric, or duodenal varices. Contrast-enhanced CT abdomen revealed an ectopic varix in the ascending colon with dilated tortuous vessel arising from superior mesenteric vein ( - Fig. 1; Video 1). Colonoscopy revealed a large polypoidal lesion in the ascending colon. Possible differential diagnosis included submucosal lesions such as lipoma, leiomyoma, GI stromal tumors, etc. However, in the presence of red color signs, being partially compressible and with corroborative CT findings, a diagnosis of ectopic varix was made (-Fig. 2; Video 1). The rest of the visualized colonic mucosa was normal without any other features of portal hypertensive colopathy. Patient was taken up for endoscopic variceal glue injection. After puncturing the varix with a 23G sclerotherapy needle, $2 \mathrm{~mL}$ of cyanoacrylate

DOI https://doi.org/

10.1055/s-0041-1733346

ISSN 0976-5042 glue was injected. Check colonoscopy done 24 hours later revealed no signs of bleeding as well as decrease in the size of the varix. The patient was discharged subsequently and is currently doing well on follow-up with no recurrence of GI bleed

\section{Video 1}

Colonoscopy done in the index case showing the presence of isolated ectopic varix with red color signs (punctum) in the ascending colon along with presence of luminal blood; contrast-enhanced $\mathrm{CT}$ abdomen showing the presence of dilated tortuous vessel in right colon (ectopic varix); colonoscopy showing the glue injection of the varix; after glue injection, regression of the varix is seen. Online content including video sequences viewable at: https://www. thieme-connect.com/products/ejournals/html/10.105 5/s-0041-1733346.

\section{Learning Objectives}

Isolated colonic varix is an incredibly rare presentation in patients with underlying cirrhosis, reported in $3.4 \%$ of cases with intrahepatic portal hypertension. ${ }^{1}$ They are usually

\section{(c) 2021. Society of Gastrointestinal Endoscopy of India.}

This is an open access article published by Thieme under the terms of the Creative Commons Attribution-NonDerivative-NonCommercial-License, permitting copying and reproduction so long as the original work is given appropriate credit. Contents may not be used for commercial purposes, or adapted, remixed, transformed or built upon. (https://creativecommons.org/licenses/by-nc-nd/4.0/).

Thieme Medical and Scientific Publishers Pvt. Ltd. A-12, 2nd Floor, Sector 2, Noida-201301 UP, India 


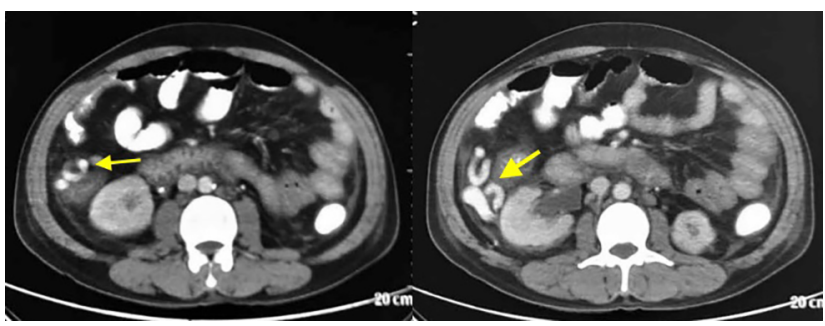

Fig. 1 Contrast enhanced CT scan showing the presence of ectopic varix in the ascending colon

known to present with obscure GI bleed, iron deficiency anemia, or diagnosed incidentally. ${ }^{2}$ Overt lower GI bleed from such isolated varices has been documented in only $1 \%$ of such cases. $^{3}$ Thus, such a clinical scenario can pose a diagnostic challenge. Two important caveats during colonoscopy in such cases are to avoid overinsufflation, in order to prevent the collapse of the varix, and care should be taken to avoid mistaking a varix for a tumor or polyp. Colonic varix can be effectively managed endoscopically by glue injection therapy, as demonstrated in our index case. In view of limited data, the management algorithm for colonic varices has not been standardized. Other management options include conservative management with somatostatin analogues, transjugular intrahepatic portosystemic shunting or surgical shunting, and even partial colectomy. ${ }^{4}$

\section{Author Contributions}

JD: conceptualizing and designing, reviewing of literature, drafting the work, and providing final approval.

JS: performing the procedure, drafting the work, and providing final approval.

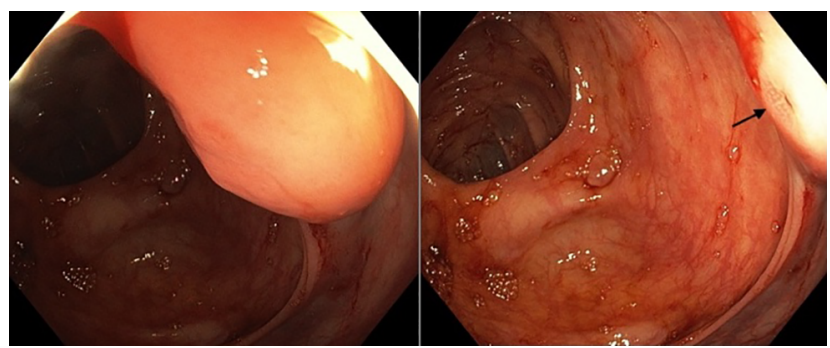

Fig. 2 Colonoscopy image showing polypoidal lesion with red color signs and punctum (black arrow) suggestive of ectopic varix

GM and RK: conception, intellectual review of the work, and final approval.

All the authors have approved the final version of the work.

\section{Funding}

None.

\section{Disclosure}

The authors declare no conflicts of interest.

\section{References}

1 McCormack TT, Bailey HR, Simms JM, Johnson AG. Rectal varices are not piles. Br J Surg 1984;71(2):163

2 Sarin SK, Kumar CKN. Ectopic varices. Clin Liver Dis (Hoboken 2012;1(5):167-172

3 Bresci G, Parisi G, Capria A. Clinical relevance of colonic lesions in cirrhotic patients with portal hypertension. Endoscopy 2006;38(8):830-835

4 Dina I, Braticevici CF. Idiopathic colonic varices: case report and review of literature. Hepat Mon 2014;14(7):e18916 